\title{
Os Projetos de Lei de Comunicação de Massa por Assinatura: controvérsias, interesses e expectativas
}

Telecommunication Sector Update

The Brazilian Pay TV reform: controversies, interests and expectations

Submetido(submitted): 25 de fevereiro de 2010

Parecer(revised): 16 de março de 2010

Miriam Wimmer*

Aceito(accepted): 5 de abril de 2010

Informe setorial

Atualizado até março de 2010

O presente estudo apresenta um panorama do atual estado das discussões referentes à elaboração de uma nova lei acerca da comunicação de massa por assinatura. Para tanto, pretende-se sintetizar os pontos mais polêmicos em debate, expor os aspectos centrais dos projetos de lei em tramitação no Congresso Nacional e, por fim, analisá-los de forma crítica sob a ótica dos diversos grupos de interesse envolvidos.

A pesquisa é baseada no texto dos projetos de lei, em notícias veiculadas na mídia especializada e nas manifestações e documentos apresentados pelas entidades participantes de audiências públicas realizadas no Congresso Nacional.

\section{Introdução: síntese dos principais pontos de debate}

A atual efervescência da discussão relativa à comunicação de massa pode ser atribuída à conjunção de diversos fatores. Em especial, a rapidez de evolução e difusão de tecnologias "convergentes" tem impulsionado a aproximação entre setores tradicionalmente considerados independentes, como a TV por assinatura, a telefonia fixa e móvel e a radiodifusão, resultando em fusões, aquisições e parcerias comerciais com vistas à oferta de serviços múltiplos ao usuário final. Nesse passo, a convergência de redes,

*Doutoranda na linha de Políticas da Comunicação da Faculdade de Comunicação da Universidade de Brasília. Mestre em Direito Público pela Universidade do Estado do Rio de Janeiro e Bacharel em Direito pela mesma instituição. Pesquisadora do Grupo de Estudos em Direito das Telecomunicações (GETEL/UnB). 
de serviços e de modelos de negócios revela, de forma incontestável, a necessidade de atualização do quadro normativo ora vigente.

Embora a discussão se prolongue já há mais de três anos, a realização da primeira Conferência Nacional de Comunicação, em dezembro de 2009, que ratificou a necessidade de atualização do marco regulatório vigente, parece ter trazido novo ânimo ao debate.

A reavaliação da regulação dos serviços de comunicação de massa por assinatura ocorre em um cenário de embate entre setores empresariais específicos - empresas de telecomunicação, de radiodifusão, de televisão por assinatura, entre outros -, e de veementes manifestações da sociedade civil, que enxerga uma oportunidade para promover avanços na democratização da comunicação e dar cumprimento às normas constitucionais relativas à comunicação social.

É possível sintetizar as questões-chave atualmente em discussão da seguinte forma:

(i) Necessidade de conferir proteção a determinados tipos de conteúdo:

- Como assegurar o respeito aos princípios constitucionais de produção e programação previstos no art. 221 da Constituição Federal e incidentes sobre todos os meios de comunicação social eletrônica (art. 222, $\left.\S 3^{\circ}\right)^{1}$ ? Por meio de cotas de produção e programação ou por meio de restrições ao capital estrangeiro?

- Caso sejam estabelecidas cotas de conteúdo, por quanto tempo devem vigorar?

- Devem ser mantidas e/ou estendidas para os demais serviços de comunicação de massa regras de "must-carry" como as atualmente previstas na Lei do Cabo? Se sim, como deve ser o relacionamento entre geradoras e prestadoras de serviços de comunicação de massa por assinatura? A veiculação de certos canais deve ser obrigatória

${ }^{1}$ Constituição Federal. Art. 221. A produção e a programação das emissoras de rádio e televisão atenderão aos seguintes princípios: I - preferência a finalidades educativas, artísticas, culturais e informativas; II - promoção da cultura nacional e regional e estímulo à produção independente que objetive sua divulgação; III regionalização da produção cultural, artística e jornalística, conforme percentuais estabelecidos em lei; IV - respeito aos valores éticos e sociais da pessoa e da família. Art. 222. $\S 3^{\circ}$ Os meios de comunicação social eletrônica, independentemente da tecnologia utilizada para a prestação do serviço, deverão observar os princípios enunciados no art. 221, na forma de lei específica, que também garantirá a prioridade de profissionais brasileiros na execução de produções nacionais.

Revista de Direito, Estado e Telecomunicações, v. 2, n. 1, p. 231-258 (2010)

DOI: https://doi.org/10.26512/1str.v2i1.21690 
ou facultativa? A disponibilização de tais canais pela geradora local deve ser onerosa ou gratuita?

- Como definir conteúdo brasileiro?

- Haverá mecanismos de fomento e incentivo à produção de conteúdo brasileiro e produções independentes?

- Devem existir limites sobre contratos de exclusividade de veiculação de determinados conteúdos?

(ii) Restrições legais e constitucionais sobre o capital estrangeiro:

- A Constituição impõe à radiodifusão limitações de capital estrangeiro (art. 222 - 30\%) de cuja eliminação, no momento, não se cogita. Tais restrições devem ser aplicadas a todos que pretendem entrar no mercado de produção e programação de conteúdo?

- Devem ser mantidas as restrições de capital estrangeiro atualmente incidentes sobre os serviços de TV a Cabo (art. $7^{\circ}$, II da Lei n. ${ }^{\circ}$ 8.977/95 ou Lei do Cabo - 49\%)? Se sim, deveriam tais limites incidir sobre todos os demais serviços de TV por assinatura?

(iii) TV por assinatura:

- Devem ser mantidas as restrições à participação de concessionárias de STFC em prestadoras de TV a Cabo (Cláusula 14.1 do Contrato de Concessão e art. 15 da Lei do Cabo)?

- É possível unificar a legislação referente à TV por assinatura, eliminando assim o tratamento diferenciado hoje conferido aos diversos serviços (MMDS, DTH, TVA, TV a Cabo, etc)?

(iv) Cadeia produtiva e divisão de competências:

- Serviços convergentes exigem reguladores convergentes?

- Quais são as etapas da cadeia produtiva e que tipo de regulação deve incidir sobre cada uma delas? Qual órgão ou entidade deve atuar em cada etapa dessa cadeia (ANATEL, ANCINE, MC, MINC, MJ, CADE, etc)?

- Qual tratamento deve ser conferido aos serviços prestados com base na internet?

(v) Necessidade de que a nova legislação propicie avanços democráticos:

- Haverá mecanismos de limitação da concentração do mercado?

- Haverá mecanismos de desverticalização da cadeia de produção?

- Haverá mecanismos que assegurem a oferta de conteúdos representativos da diversidade e pluralidade da sociedade brasileira? 
- Haverá ampliação do controle social sobre os meios de comunicação de massa?

Os diversos projetos de lei atualmente em discussão tratam de forma e com abrangência distintas os pontos acima relacionados. Os variados enfoques são a seguir sucintamente descritos.

\section{Os projetos de lei: tramitação e principais aspectos}

A discussão sobre o novo marco legal para a comunicação de massa por assinatura, atualmente centrada sobre o PL 29/2007 e seus substitutivos, tem origem em cinco projetos de lei em discussão no Congresso Nacional.

No Senado, tramita o PLS 280/2007, do Senador Flexa Ribeiro (PSDB/PA).

Na Câmara dos Deputados, tramitam o PL 70/2007, do Deputado Marquezelli (PTB/SP), o PL 332/2007, do Deputado Paulo Teixeira (PT/SP) e o PL 1908/2007, do Deputado João Maia (PL/RN), todos apensados ao PL 29/2007, do Deputado Bornhausen (DEM/SC), este último objeto de diversos substitutivos apresentados nas diferentes comissões da Câmara por onde passou até o momento.

O Projeto de Lei do Senado n. ${ }^{\circ}$ 280/2007 foi apresentado em maio de 2007 e desde então circulou pela Comissão de Educação, sob relatoria de Sérgio Zambiasi (PTB/RS), passou pela Comissão de Assuntos Econômicos, sob relatoria do Senador Aloizio Mercadante (PT/SP), e, desde fevereiro de 2010, aguarda designação de relator na Comissão de Serviços de Infraestrutura. Deverá ainda passar pela Comissão de Ciência, Tecnologia, Inovação, Comunicação e Informática, cabendo a esta emitir decisão terminativa.

Já no que tange aos PLs da Câmara dos Deputados, como acima referido, todos tramitam apensados ao PL 29, do Deputado Paulo Bornhausen (DEM/SC). A tramitação do projeto de lei tem sido repleta de idas e vindas, frustrando as expectativas daqueles que esperavam uma aprovação célere.

Após a apresentação do PL 29 no plenário, em fevereiro de 2007, o projeto foi encaminhado à Comissão de Ciência e Tecnologia, Comunicação e Informática (CCTCI) e foram a ele apensados os demais PLs. Foi então 
encaminhado à Comissão de Desenvolvimento Econômico, Indústria e Comércio (CDEIC) em junho de 2007, onde foi designado como relator o Deputado Wellington Fagundes (PR/MT). Após apresentação de substitutivo pelo Deputado Relator, o PL 29 foi encaminhado novamente à CCTCI, em novembro de 2007, onde foi designado como relator o Deputado Jorge Bittar (PT/RJ). O substitutivo longamente negociado pelo Deputado Jorge Bittar, na CCTCI, não chegou, contudo, a ser votado, pois a Presidência da Câmara aprovou requerimento, formulado pelo Deputado Cezar Silvestri (PPS/PR), para que o projeto fosse submetido à apreciação da Comissão de Defesa do Consumidor (CDC) antes da deliberação pela CCTCI.

Desse modo, o PL 29 - ainda na versão anterior, elaborada na CDEIC, sem considerar a proposta do Deputado Jorge Bittar - foi redistribuído para a CDC em setembro de 2008, sob relatoria do Deputado Vital do Rego Filho (PMDB/PB), que apresentou parecer e substitutivo.

O PL 29 retornou à CCTCI um ano depois, em setembro de 2009, onde, sob relatoria do Deputado Paulo Henrique Lustosa (PMDB/CE), foi elaborado novo substitutivo. Essa versão foi encaminhada à Comissão de Constituição e Justiça e de Cidadania (CCJC), onde passou a ser relatado pelo Deputado Eduardo Cunha (PMDB-RS). Em 16 de março de 2010 foi divulgado o voto do relator, contendo emendas supressivas com relação a pontos específicos do PL.

Nas comissões da Câmara por onde circulou, o projeto foi alvo de centenas de emendas, dos mais diversos teores. A Tabela 1 expõe os aspectos mais distintivos dos cinco projetos originalmente apresentados e do último substitutivo do PL 29, que serão, subsequentemente, objeto de análise individualizada. 
Tabela 1 - Sistematização dos principais pontos dos projetos de lei

\begin{tabular}{|c|c|c|c|c|c|}
\hline & Objeto & $\begin{array}{c}\text { Etapas da cadeia } \\
\text { produtiva }\end{array}$ & $\begin{array}{l}\text { Limite ao capital } \\
\text { estrangeiro }\end{array}$ & Cotas & TV a Cabo \\
\hline 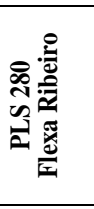 & $\begin{array}{l}\text { Produção, } \\
\text { programação e } \\
\text { provimento de } \\
\text { conteúdo } \\
\text { brasileiro para } \\
\text { distribuição por } \\
\text { meio eletrônico } \\
\end{array}$ & $\begin{array}{l}\text { - produçãa } \\
\text { - programação } \\
\text { - provimento } \\
\text {-distribuição }\end{array}$ & $\begin{array}{l}49 \% \text { na produção, } \\
\text { programação e } \\
\text { provimento }\end{array}$ & Não & $\begin{array}{l}\text { - revogação limite ao capital } \\
\text { - } 10 \text { anos carência para } \\
\text { concessionárias de STFC }\end{array}$ \\
\hline 事莺 & $\begin{array}{l}\text { Produção, } \\
\text { programação e } \\
\text { provimento de } \\
\text { conteúdo } \\
\text { nacional }\end{array}$ & $\begin{array}{l}\text { - produção } \\
\text { - programação e } \\
\text { provimento } \\
\text {-distribuição }\end{array}$ & $\begin{array}{l}30 \% \text { na produção, } \\
\text { programação e } \\
\text { provimento }\end{array}$ & Não & Não trata \\
\hline 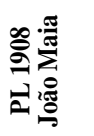 & $\begin{array}{l}\text { Serviço de } \\
\text { comunicação } \\
\text { eletrônica de } \\
\text { massa }\end{array}$ & $\begin{array}{l}\text { - produçãa } \\
\text { - programaçãa } \\
\text { - provimento } \\
\text {-distribuição }\end{array}$ & $\begin{array}{l}\text { Mantém restrições } \\
\text { atuais para cabo e } \\
\text { radiodifusão }\end{array}$ & Sim & $\begin{array}{l}\text { As atuais prestadoras poderão } \\
\text { migrar para o SCEM }\end{array}$ \\
\hline 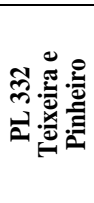 & $\begin{array}{l}\text { Produção, } \\
\text { programação, } \\
\text { provimento, } \\
\text { empacotamento e } \\
\text { distribuição de } \\
\text { comunicação } \\
\text { social eletrônica }\end{array}$ & $\begin{array}{l}\text { - produção } \\
\text { - programação } \\
\text { - provimento } \\
\text { - empacotamento } \\
\text { - distribuição }\end{array}$ & $\begin{array}{l}\text { Mantém restrições } \\
\text { atuais para cabo e } \\
\text { radiodifusão }\end{array}$ & Sim & Não trata \\
\hline 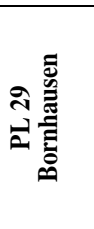 & $\begin{array}{l}\text { Organização e } \\
\text { exploração das } \\
\text { atividades de } \\
\text { comunicação } \\
\text { social eletrônica }\end{array}$ & $\begin{array}{l}\text { - produção } \\
\text { - programação } \\
\text { - provimento } \\
\text {-distribuição }\end{array}$ & $\begin{array}{l}\text { Mantém restrição } \\
\text { atual para } \\
\text { radiodifusão }\end{array}$ & Não & $\begin{array}{l}\text { - revoga limite ao capital } \\
\text { - possibilidade de obtenção } \\
\text { de outorga de TV a Cabo por } \\
\text { concessionárias de STFC em } \\
\text { qualquer localidade onde não } \\
\text { haja outorga e onde já houver } \\
\text { outorga há pelo menos um } \\
\text { ano }\end{array}$ \\
\hline 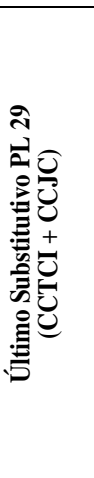 & $\begin{array}{l}\text { Comunicação } \\
\text { audiovisual de } \\
\text { acesso } \\
\text { condicionado }\end{array}$ & $\begin{array}{l}\text { - produção } \\
\text { - programaçãa } \\
\text { - empacotamento } \\
\text { - distribuição }\end{array}$ & $\begin{array}{l}\text { - Limitações à } \\
\text { propriedade } \\
\text { cruzada entre } \\
\text { teles, empresas de } \\
\text { radiodifusão, } \\
\text { produtoras e } \\
\text { programadoras } \\
\text { com sede no } \\
\text { Brasil. } \\
\text { - Produção e } \\
\text { empacotamento } \\
\text { sob } \\
\text { responsabilidade } \\
\text { de brasileiros } \\
\text { natos ou } \\
\text { naturalizados há } \\
10 \text { anos. }\end{array}$ & Sim & $\begin{array}{l}\text { - Revogação parcial da Lei do } \\
\text { Cabo, eliminando a limitação } \\
\text { ao capital estrangeiro. } \\
\text { - Outorgas existentes } \\
\text { permanecem em vigor, } \\
\text { devendo adaptar-se às } \\
\text { disposições da nova lei. } \\
\text { - Possibilidade de migração } \\
\text { das atuais prestadoras para o } \\
\text { Serviço de Acesso } \\
\text { Condicionado. } \\
\text { - Concessionárias de STFC } \\
\text { podem prestar SAC, } \\
\text { observadas as restrições do } \\
\text { PL }\end{array}$ \\
\hline
\end{tabular}

Revista de Direito, Estado e Telecomunicações, v. 2, n. 1, p. 231-258 (2010)

DOI: https://doi.org/10.26512/1str.v2i1.21690 
Deve-se ressaltar que embora o debate sobre cada PL, individualmente considerado, tenha sido superado pela evolução posterior do PL 29, a análise das principais características dos cinco PLs "originários" revela muito sobre os diferentes interesses em jogo no debate parlamentar.

\section{PLS 280/07 do Senador Flexa Ribeiro: a defesa do conteúdo brasileiro por meio da restrição ao capital estrangeiro}

O Projeto de Lei do Senador Flexa Ribeiro (PSDB/PA) se fundamenta na visão (coincidente com aquela defendida pelos radiodifusores) de que a produção cultural é crítica para a soberania nacional e que também se tornou importante elemento de desenvolvimento econômico.

Nessa linha, oferece uma definição bastante ampla de "conteúdo brasileiro" 2 fazendo incidir sobre as atividades de produção, programação e provimento de tal conteúdo restrições quanto ao capital estrangeiro: segundo o projeto, tais atividades somente podem ser desempenhadas por brasileiros natos ou naturalizados há mais de 10 anos, ou de pessoas jurídicas constituídas sob as leis brasileiras e que tenham sede no País, nas quais $\mathbf{5 1 \%}$ do capital total e do capital votante pertençam, direta ou indiretamente, a brasileiros natos ou naturalizados há mais de 10 anos.

Aos atores do mercado que não atendam a estes requisitos - prestadores de serviços de telecomunicações, fixos ou móveis, ainda que envolvam internet, portais, sítios ou qualquer outro serviço de valor adicionado - é permitida apenas a atividade de distribuição por meio eletrônico envolvendo conteúdo brasileiro, quando este for produzido, programado e provido por quem os atenda. A única exceção diz respeito a atividades de produção, programação e provimento de conteúdo brasileiro que sejam efetuadas em caráter eventual e que não propiciem, direta ou indiretamente, a seu responsável, qualquer vantagem econômica.

${ }^{2}$ Segundo o PLS 280/07, conteúdo brasileiro é aquele: I - direcionado originalmente
ao público brasileiro, em especial quando produzido em língua portuguesa, no todo
ou em parte significativa, inclusive por meio de dublagem; ou II - que envolva
participação significativa de profissionais brasileiros, tais como autores, roteiristas,
diretores, jornalistas, apresentadores, locutores, atores ou outros artistas; ou III - que
contenha sons e imagens da transmissão de eventos realizados no território nacional
ou dos quais brasileiros participem de forma preponderante, nos campos cultural,
artístico ou desportivo.

Revista de Direito, Estado e Telecomunicações, v. 2, n. 1, p. 231-258 (2010) DOI: https://doi.org/10.26512/lstr.v2i1.21690 
No que concerne à Lei do Cabo, o projeto determina que a geradora local poderá decidir sobre a distribuição de seu sinal nas redes de TV a cabo. Dito de outro modo, o "must carry" se torna um "may carry", a critério da geradora.

O PL propõe a revogação do inciso II do art. $7^{\circ}$ da Lei do Cabo, eliminando assim a limitação à participação de capital estrangeiro que atualmente dificulta a entrada das empresas de telecomunicações no mercado de TV a cabo. Em contrapartida, estabelece um período de carência de 10 anos para que as concessionárias de STFC explorem serviço de TV a Cabo em suas respectivas áreas de serviço, salvo nas localidades em que não exista outorga em vigor.

\section{PL 70/2007 do Deputado Nelson Marquezelli: a defesa do conteúdo brasileiro por meio de restrições ainda maiores ao capital estrangeiro}

Assim como o PLS 280/07, o PL 70, do Deputado Nelson Marquezelli (PTB/SP) também se encontra alinhado aos interesses dos empresários do setor de radiodifusão. O projeto tem por objetivos declarados assegurar a defesa da soberania e da identidade nacionais, incluindo o desenvolvimento da cultura e a proteção do patrimônio cultural brasileiros; e a manutenção do pluralismo e da liberdade de circulação de idéias, exigindo a prevenção de condutas anticoncorrenciais no setor.

O projeto define de modo amplo o "conteúdo nacional"3 e divide sua cadeia de valor em três etapas - (i) produção; (ii) programação e provimento; e (iii) distribuição de conteúdo. A principal característica do PL é estender, a qualquer empresa que queira entrar no mercado de produção, programação e provimento de conteúdo nacional, o limite de capital estrangeiro incidente sobre radiodifusão. Assim, tais atividades

\footnotetext{
${ }^{3}$ Segundo o PL, Conteúdo Nacional é: a) o produzido ou fixado, no todo ou em parte significativa, em língua portuguesa; b) aquele do qual participem, de forma preponderante, autores, roteiristas, diretores, jornalistas, apresentadores, locutores, atores ou outros artistas brasileiros; c) o que contenha sons e imagens da transmissão de eventos culturais, esportivos, entre outros, realizados no território nacional ou dos quais participem, de forma preponderante, brasileiros que atuem no campo cultural, artístico, desportivo ou qualquer outro; ou d) o direcionado originalmente aos brasileiros, independentemente do idioma utilizado, de dublagem ou legendação para a língua portuguesa.
}

Revista de Direito, Estado e Telecomunicações, v. 2, n. 1, p. 231-258 (2010)

DOI: https://doi.org/10.26512/1str.v2i1.21690 
somente poderão ser exploradas por brasileiros natos ou naturalizados há mais de dez anos, ou por pessoas jurídicas constituídas sob as leis brasileiras, nas quais ao menos $\mathbf{7 0 \%}$ do capital total e do capital votante deverão pertencer, direta ou indiretamente, a brasileiros natos ou naturalizados há mais de dez anos. Ademais, a gestão das empresas, a responsabilidade editorial e as atividades de seleção e direção de programação são privativas do sócio ou grupo de sócios controladores brasileiros, que as exercerão diretamente ou por meio de representantes que, em qualquer caso, serão obrigatoriamente brasileiros natos ou naturalizados há mais de dez anos.

Embora a atividade de distribuição de conteúdo nacional compreendida como a entrega de programação aos usuários através de qualquer meio eletrônico - não esteja sujeita a tais limites, o projeto veda à empresa que exerce a atividade de distribuição sobrepor, tornar disponível simultaneamente, ou de qualquer forma associar ao conteúdo nacional patrocínio, publicidade, interatividade, comercialização de produtos ou de serviços. Em outras palavras, o distribuidor de conteúdo brasileiro não poderá auferir receitas advindas da inserção de publicidade.

\section{PL 1908/2007 do Deputado João Maia: a abertura do mercado às "teles" e a proteção do pluralismo e do conteúdo nacional por meio de cotas}

A marca distintiva do PL 1908/2007, do Deputado João Maia (PR/RN), é a opção por tratar apenas de serviços de televisão por assinatura. Segundo sua exposição de motivos, o projeto pretende estabelecer um novo marco regulatório suportado por uma regulamentação de serviços convergentes que possibilite (i) competição, redução de preços e novos investimentos; (ii) expansão da oferta de TV por assinatura para as classes sociais e municípios ainda não atendidos; (iii) a aceleração da universalização da banda larga nos domicílios de menor renda; (iv) o aumento da oferta de conteúdo digital eletrônico utilizando plataformas de distribuição de última geração; e (v) o aumento da oferta de conteúdo eletrônico brasileiro e o incentivo dos produtores independentes, para garantir o acesso da sociedade a uma ampla diversidade de conteúdos, preservando as culturas nacional, regional e local.

O PL cria um novo serviço de televisão por assinatura denominado "serviço de comunicação eletrônica de massa", definido como um serviço 
de telecomunicações que possibilita a distribuição de conteúdo eletrônico estruturado em uma grade de programação, ao público em geral, com acesso mediante contrato de assinatura do serviço e com interatividade, por meio de qualquer tecnologia. Segundo o PL, a comunicação eletrônica de massa é dividida em quatro etapas: (i) produção; (ii) programação; (iii) provimento; e (iv) distribuição.

Se, por um lado, o projeto não estabelece qualquer restrição de capital estrangeiro nas empresas de telecomunicações que produzam, programem, provejam ou distribuam conteúdo eletrônico por meio do serviço de comunicação eletrônica de massa, por outro, o projeto procura incentivar a desverticalização do setor de TV por assinatura e proteger o conteúdo brasileiro $^{4}$ por meio do estabelecimento de cotas de produção e programação. Assim, a programação distribuída através do serviço de comunicação eletrônica de massa deverá conter em sua grade pelo menos $50 \%$ de conteúdo brasileiro, sendo que deste percentual $10 \%$ deverá ser produzido por produtores independentes brasileiros ${ }^{5}$.

Por fim, o projeto determina que as geradoras de radiodifusão de som e imagem em VHF ou UHF abertos e não codificados deverão tornar disponível o seu sinal de forma não onerosa para as empresas prestadoras do serviço de comunicação eletrônica de massa, a seu pedido. Também aqui a lógica do "must-carry" existente na TV a Cabo é invertida, transformando-

${ }^{4}$ Segundo o PL, para que determinado conteúdo seja classificado como Conteúdo Eletrônico Brasileiro, deve: a) ser produzido em língua portuguesa por empresa produtora brasileira ou por produtor independente; ou b) ter participação majoritária de profissionais brasileiros tais como autores, roteiristas, diretores, atores, apresentadores, locutores, jornalistas ou outros artistas; ou c) conter sons e imagens de transmissão em língua portuguesa de eventos culturais,esportivos,entre outros realizados no território nacional, dos quais participem majoritariamente brasileiros que atuem nas áreas de cultura,artística ou desportiva; ou d) ser realizado em regime de co-produção por empresa brasileira ou produtor independente brasileiro em associação com empresas de outros países com os quais o Brasil não mantenha acordo de coprodução, assegurada a titularidade de no mínimo $40 \%$ dos direitos patrimoniais da obra à empresa ou ao produtor independente brasileiro e utilizar para sua produção dois terços de artistas ou técnicos brasileiros ou residentes no Brasil há mais de 3 anos.

${ }^{5}$ Para o PL, Produtor Independente Brasileiro é todo aquele brasileiro ou residente no Brasil há mais de três anos, que produza conteúdo eletrônico e que não esteja ligado juridicamente à empresas jornalísticas, de rádio e TV ou de Internet.

Revista de Direito, Estado e Telecomunicações, v. 2, n. 1, p. 231-258 (2010)

DOI: https://doi.org/10.26512/1str.v2i1.21690 
se num "may-carry" gratuito a critério da prestadora de serviço de televisão por assinatura.

\section{PL 332/2007, dos Deputados Paulo Teixeira e Walter Pinheiro: a proteção do pluralismo e do conteúdo nacional por meio de cotas}

O PL 332/07, dos Deputados Paulo Teixeira (PT/SP) e Walter Pinheiro (PT/BA), se propõe a tratar da "produção, programação, provimento, empacotamento e distribuição de comunicação social eletrônica" com o escopo de propiciar a multiplicidade de acesso a dados e informações, o desenvolvimento dos mercados de produção de informação e a inclusão digital, por meio da criação de mecanismos de prevenção à concentração do poder econômico capaz de ensejar a diminuição das fontes de produção e circulação de informação.

Uma das novidades neste projeto é a introdução do conceito de "empacotamento", definido como "a atividade de definição do formato de apresentação da programação".

O projeto separa a "comunicação social eletrônica por radiodifusão", definida como a transmissão unidirecional terrestre, por radiofreqüências em propagação pelo espaço, de conteúdo eletrônico determinado pelo emissor para recepção direta e livre pelo público em geral, da "comunicação social eletrônica de acesso condicionado", definida como a transmissão de conteúdo eletrônico, o qual admite interação, cuja recepção é condicionada à contratação prévia. A transmissão de comunicação social eletrônica de acesso condicionado pode ser dar por meio de serviços como TV a Cabo, DTH, MMDS, DTH, SMP, STFC e SCM.

Não há, no projeto, menção específica sobre o capital estrangeiro. Assim, mantêm-se as restrições incidentes sobre radiodifusão e sobre o serviço de TV a Cabo, perpetuando as assimetrias entre serviços de TV por assinatura.

No que diz respeito à proteção do pluralismo e do conteúdo nacional, o PL estabelece que os serviços de TV a Cabo, MMDS, DTH, SMP, STFC e SCM deverão destinar percentual não inferior a $15 \%$ de sua capacidade operacional alocada à comunicação social eletrônica de acesso condicionado, para veiculação de conteúdo produzido por empresas brasileiras, na forma do regulamento. As emissoras de radiodifusão sonora e de sons e imagens, por sua vez, deverão reservar $30 \%$ da programação 
veiculada a produções culturais, artísticas e jornalísticas regionais. Além disso, o agente econômico que atuar concomitantemente nos segmentos de programação e distribuição não poderá veicular apenas os conteúdos que produzir, devendo adquirir conteúdos de terceiros, preferencialmente de produtores de diferentes regiões do País.

Por fim, um ponto interessante: esse Projeto de Lei é o único que leva em conta o processo de digitalização da radiodifusão, ao reservar, em caso de disponibilidade, cinco canais da TV Digital para a educação, cultura, cidadania, saúde e poderes executivo, legislativo e judiciário.

\section{PL 29/07 do Deputado Bornhausen: a abertura do mercado de comunicação social eletrônica às empresas de telecomunicações}

O PL 29/07, de tônica bastante liberal, visava, em sua versão original, a fomentar a disponibilização generalizada, em diferentes plataformas tecnológicas, do acesso ao conteúdo eletrônico por meio de múltiplas prestadoras de serviços de telecomunicações que distribuem tais conteúdos em competição entre si. Assim, buscava simplesmente eliminar da legislação atual os entraves à entrada das empresas de telecomunicação no negócio da produção e programação de conteúdo.

O PL originalmente definiu Comunicação Social Eletrônica como o conteúdo eletrônico a ser distribuído por serviços de telecomunicações como a radiodifusão, a TV a Cabo, o DTH, o MMDS, o SCM, o SMP, bem como por outros serviços definidos pela Anatel.

Note-se que a inclusão da radiodifusão como um serviço de telecomunicações que distribui comunicação social eletrônica, coerentemente com a classificação dada pelo Código Brasileiro de Telecomunicações (Lei n. ${ }^{\circ}$ 4.117/62), geraria como importante conseqüência a transferência à Anatel da competência para disciplinar e fiscalizar a radiodifusão no que tange à distribuição de conteúdo eletrônico, bem como no que concerne à programação e ao provimento de conteúdo eletrônico, no que configure infração à ordem econômica no setor de telecomunicações.

A atividade de Comunicação Social Eletrônica foi separada, pelo PL, em quatro etapas: (i) produção, (ii) programação, (iii) provimento e (iv) distribuição de conteúdo eletrônico. Segundo o PL, qualquer prestadora de serviços de telecomunicações, incluindo radiodifusão, poderia participar de 
qualquer etapa da cadeia de valor da comunicação social eletrônica, sem restrições.

No que tange ao capital estrangeiro, o PL originalmente era igualmente marcado pela liberalização. Não havia limite de capital estrangeiro para empresas de telecomunicações, desde que constituídas no país, embora o Executivo pudesse estabelecer limites se assim julgasse necessário.

Por fim, no que tange à Lei do Cabo, o projeto revogava a limitação de $49 \%$ de capital estrangeiro em empresas de TV a cabo, bem como o dispositivo que determina que concessionárias de telecomunicações somente podem operar TV a cabo em caso de desinteresse manifesto de empresas privadas. Em paralelo, foi introduzido artigo permitindo que concessionárias de STFC obtivessem concessão para explorar o serviço de TV a cabo em qualquer localidade onde não existisse outorga de cabo na data de entrada em vigor da lei e onde já houvesse sido outorgada concessão de serviço de TV a cabo há pelo menos um ano.

\section{A evolução do PL 29 ao longo da tramitação legislativa}

\section{Parecer da CDEIC}

Como antes mencionado, o PL 29, ao qual se encontram apensados os demais PLs que tramitam na Câmara dos Deputados, foi inicialmente apreciado pela Comissão de Desenvolvimento Econômico, Indústria e Comércio sob a relatoria do Deputado Wellington Fagundes.

O Deputado Wellington Fagundes apresentou três substitutivos. Sua proposta inicial continha 4 elementos principais: (i) harmonização da regulamentação de TV a cabo e via satélite no País, com o intuito de introduzir uma regulação neutra do ponto de vista tecnológico; (ii) viabilização da competição no segmento de TV por assinatura em seus diversos níveis (produção, programação, empacotamento e distribuição), por meio da introdução do conceito de poder de mercado significativo (PMS); (iii) possibilidade de o órgão regulador avaliar a oportunidade e conveniência de impor obrigações de acesso (remunerado) sobre a infraestrutura das prestadoras do serviço de TV por assinatura e de telecomunicações; e (iv) promoção da pluralidade de opiniões, da diversidade cultural e das identidades regionais e nacional através dessas 
mídias, por meio do estabelecimento de cotas de conteúdos específicos a serem transmitidos na TV por assinatura.

Apreciadas as diversas emendas, o Deputado recuou em alguns pontos, introduzindo restrições à entrada das teles no mercado de conteúdo, retirando as obrigações de acesso às redes e das disposições quanto ao PMS e especificando uma cota de $50 \%$ de conteúdo nacional no empacotamento de canais, sendo $10 \%$ de produção independente brasileira.

\section{Discussão na CCTCI}

Encaminhado o projeto à Comissão de Ciência, Tecnologia, Comunicação e Informática, o relator Jorge Bittar apresentou, em 07 de dezembro de 2007, seu parecer com substitutivo. A linha condutora de sua proposta era a alteração do modelo de negócios do setor e o fomento a produção de conteúdo audiovisual nacional, de modo a introduzir competição entre os distribuidores de conteúdo, provocando uma queda de preços que resultaria, presumivelmente, no aumento da base de assinantes.

Nessa linha, o projeto dividiu a cadeia de valor em quatro etapas - (i) produção; (ii) programação; (iii) empacotamento; e (iv) distribuição estabelecendo determinadas restrições de capital tendentes a evitar a concentração de mercado e a proteger o conteúdo nacional.

Assim, o substitutivo estabeleceu regras para impedir que existissem relações de controle entre empresas de telecomunicações e produtoras e programadoras nacionais. Segundo o substitutivo apresentado, (a) as concessionárias e permissionárias de radiodifusão, bem como as produtoras e programadoras nacionais, não poderiam, direta ou indiretamente, deter maioria simples do capital votante das prestadoras de serviços de telecomunicações de interesse coletivo que se interconectam à rede pública; e, simetricamente, $(b)$ as prestadoras de serviços de telecomunicações de interesse coletivo que se interconectam à rede pública não poderiam, direta ou indiretamente, deter maioria simples do capital votante das produtoras e programadoras nacionais, bem como das permissionárias de radiodifusão.

Além disso, definiu que os programadores de canais que veiculem majoritariamente conteúdos jornalísticos não poderiam deter, direta ou indiretamente, mais do que $20 \%$ de participação cruzada nos seus capitais votantes. 
No que tange ao capital estrangeiro, embora o substitutivo do Deputado Jorge Bittar tenha definido que as atividades de produção, programação e empacotamento seriam livres para empresas brasileiras com sede e administração no país, apenas seria considerada produtora nacional a empresa (i) brasileira que (ii) tivesse sede e administração no país, em que (iii) a maioria do capital votante fosse de titularidade direta ou indireta de brasileiros natos ou naturalizados há mais de dez anos e em que (iv) a gestão das atividades da empresa, a responsabilidade editorial e a seleção e direção dos conteúdos produzidos fossem privativas de brasileiros. Do mesmo modo, apenas seria considerada programadora nacional a empresa que atendesse aos três primeiros requisitos acima enumerados e cuja gestão, responsabilidade editorial e seleção dos conteúdos fossem privativas de brasileiros. Além disso, a gestão, a responsabilidade editorial e as atividades de seleção e direção associadas à produção de conteúdo nacional, à programação e ao empacotamento seriam privativas de brasileiros.

A grande novidade do projeto apresentado pelo Deputado Jorge Bittar foi o avanço na delimitação de cotas de conteúdo e a introdução do conceito de espaço qualificado ${ }^{6}$ dentro de cada canal. O relator desenvolveu um intrincado sistema de cotas, envolvendo não só cotas de empacotamento, mas também cotas para as programadoras, ou seja, cotas de conteúdo dentro de cada canal individual. Assim, buscou incentivar a difusão de conteúdo nacional e a participação de produtoras nacionais independentes, programadoras nacionais e programadoras nacionais independentes. Restringiu também o tempo destinado à publicidade comercial em cada canal de programação e estabeleceu mecanismos para impedir que os percentuais de cotas fossem exibidos apenas em horários de baixa audiência. Incluiu, ademais, obrigações de oferta isonômica, não discriminatória e não exclusiva de conteúdos audiovisuais eletrônicos, canais de programação e direitos de exploração de eventos nacionais insubstituíveis que fossem considerados relevantes no mercado de televisão por assinatura.

${ }^{6}$ Espaço qualificado é definido da seguinte forma: "espaço total do canal de programação excluindo-se programas jornalísticos, religiosos, políticos, manifestações e eventos esportivos, concursos, publicidade, televendas, propaganda política obrigatória e conteúdo audiovisual eletrônico veiculado em horário eleitoral gratuito". 
Segundo a proposta apresentada por Bittar, seriam mantidas obrigações de "must-carry" gratuito, porém deixou-se aberta a possibilidade de os órgãos reguladores das telecomunicações e do audiovisual, conjuntamente, determinarem a não obrigatoriedade da distribuição dos canais nos meios de distribuição considerados inapropriados para o seu transporte (como é, por exemplo, o caso do SMP).

Por fim, nas disposições transitórias, o projeto previu a revogação da Lei do Cabo e a extinção das autorizações de MMDS e de DTH, possibilitando a migração sem ônus das atuais prestadoras desses dois últimos serviços para o serviço de acesso condicionado. As prestadoras de TV a Cabo e de TVA poderiam optar entre manter suas outorgas em vigência até o término de seus contratos, ou poderiam migrar para o novo serviço de acesso condicionado.

Como mencionado anteriormente, a versão do PL negociada por Jorge Bittar não chegou a ser votada na CCTCI, pois foi aprovado requerimento para que o projeto fosse submetido à apreciação da Comissão de Defesa do Consumidor (CDC) antes da deliberação pela CCTCI.

\section{Parecer da CDC}

$\mathrm{Na}$ Comissão de Defesa do Consumidor, contudo, o Deputado Relator Vital Rêgo Filho inseriu em sua proposta algumas das idéias que haviam sido negociadas por Jorge Bittar, incluindo a proposta de cotas de conteúdo debatida na CCTCI, que não havia sido aprofundada na versão do PL oriunda da CDEIC.

Outros pontos relevantes constantes do parecer da CDC foram os seguintes: (i) inclusão, no escopo do PL, dos conteúdos audiovisuais distribuídos pela internet cujo acesso fosse condicionado a contratação remunerada por assinantes ${ }^{7}$; (ii) restrições à participação cruzada entre empresas de telecomunicações, empresas de produção e de programação de

\footnotetext{
${ }^{7}$ Nesse sentido, o PL definiu da seguinte forma o Serviço de Comunicação Audiovisual Eletrônica por Assinatura: "serviço de telecomunicações de interesse coletivo, prestado no regime privado, cuja recepção é condicionada à contratação remunerada por assinantes e destinado à distribuição de conteúdos audiovisuais, de pacotes ou de canais de distribuição obrigatória, por meio de tecnologias, processos, meios eletrônicos e protocolos de comunicação quaisquer, inclusive protocolos de Internet".
} 
conteúdo audiovisual eletrônico brasileiro, e empresas de radiodifusão; (iii) inclusão de normas de defesa do consumidor, inlcusive no que se refere à questão do ponto-extra da TV por assinatura; (iv) flexibilização do artigo 86 da LGT (que atualmente determina que a concessionária de STFC não pode explorar outros serviços de telecomunicações) para permitir que o serviço de comunicação audiovisual eletrônica por assinatura fosse prestado por qualquer tipo de empresa de telecomunicações; e $(v)$ concessão de prazo de dois anos para que programadores e empacotadores de conteúdo implantem as cotas de conteúdo previstas no PL.

Em particular, a inclusão da referência aos serviços prestados pela internet gerou grande polêmica e enfrentou resistência por parte de diversos segmentos empresariais.

É importante notar que enquanto se fortalecia a discussão parlamentar sobre cotas de conteúdo, começou-se igualmente a debater a possibilidade de separar o PL 29 em dois PLs distintos: um PL para simplesmente flexibilizar as limitações existentes à entrada das teles no mercado de conteúdo, e outro para definir regras relacionadas ao fomento e à proteção do pluralismo do conteúdo. Nessa linha, em setembro de 2008, a Consultoria Jurídica do Ministério das Comunicações encaminhou à Câmara dos Deputados parecer sugerindo que seria mais adequado que as políticas de fomento para o audiovisual fossem segregadas do PL 29 e tratadas em lei própria.

\section{Parecer da CCTCI}

O PL 29 foi encaminhado, em setembro de 2009, novamente à Comissão de Ciência e Tecnologia, Comunicação e Informática, onde foi designado como relator o Deputado Paulo Henrique Lustosa. No curto prazo de três meses, o Deputado produziu três pareceres e conseguiu negociar a aprovação de substitutivo ao PL. Os destaques propondo a supressão da política de cotas audiovisuais foram rejeitados.

A versão do PL 29 aprovada pela CCTCI acabou mantendo grande parte das idéias que haviam sido negociadas pelo Deputado Jorge Bittar.

Foi mantida, por exemplo, a divisão da cadeia produtiva em quatro etapas - produção, programação, empacotamento e distribuição - e foram mantidas regras para evitar a propriedade cruzada entre empresas de telecomunicações e empresas de radiodifusão. Tais regras, entretanto, 
sofrerarm algumas modificações. Segundo a versão da CCTCI, (a) as concessionárias e permissionárias de radiodifusão, bem como as produtoras e programadoras com sede no Brasil, não podem, direta ou indiretamente, deter controle ou titularidade de participação superior a $\mathbf{5 0 \%}$ (cinqüenta por cento) do capital total e votante de prestadoras de serviços de telecomunicações de interesse coletivo; e $(b)$ as prestadoras de serviços de telecomunicações de interesse coletivo não podem, direta ou indiretamente, deter controle ou titularidade de participação superior a $\mathbf{3 0 \%}$ (trinta por cento) do capital total e votante de concessionários e permissionárias de radiodifusão e de produtoras e programadoras com sede no Brasil. Relevante notar que essa regra, nos substitutivos anteriores, aplicava-se a empresas de produção e programação brasileiras, e que na versão da CCTCI a regra passa a valer para quaisquer empresas de produção e programação com sede no país, mesmo que de capital predominantemente estrangeiro.

Um dos pontos que havia sido alvo de polêmicos na CDC - a aplicabilidade ou não do PL aos serviços prestados com base na internet acabou não recebendo tratamento explícito. Conforme o substitutivo, o Serviço de Acesso Condicionado (SAC) é definido como "serviço de telecomunicações de interesse coletivo, prestado no regime privado, cuja recepção é condicionada à contratação remunerada por assinantes e destinado à distribuição de conteúdos audiovisuais na forma de pacotes, de canais nas modalidades avulsa de programação e avulsa de conteúdo programado e de canais de distribuição obrigatória, por meio de tecnologias, processos, meios eletrônicos e protocolos de comunicação quaisquer". Assim, embora o texto deixe claro que não há restrição a nenhum tipo de rede ou protocolo de comunicação, acaba recaindo sobre a Anatel a responsabilidade de definir se, de fato, serviços prestados com base na internet podem ou não ser considerados SAC.

Outra proposta da CDC que não foi mantida na versão do PL aprovada pela CCTCI foi a estipulação de regras sobre ponto extra. O relator explicitamente se manifestou no sentido de que não se deveria tratar em lei matéria que é objeto de regulamentação infralegal.

Com relação às cotas de conteúdo, manteve-se a idéia do "espaço qualificado", acrescentando-se, ademais, os conceitos de "canal de espaço qualificado" e "canal brasileiro de espaço qualificado". Pretende-se, com isso, dar tratamento diferenciado àqueles espaços cujo conteúdo demande Revista de Direito, Estado e Telecomunicações, v. 2, n. 1, p. 231-258 (2010) 
certo grau de produção e, portanto, seja capaz de atrair investimentos e gerar empregos qualificados.

Houve, ademais, a diferenciação dos seguintes atores: (i) produtora brasileira; (ii) produtora brasileira independente; (iii) programadora brasileira; e (iv) programadora brasileira independente.

Para que um uma produtora ou programadora seja qualificada como "brasileira", é necessário atender às seguintes exigências: (a) ser constituída sob as leis brasileiras; $(b)$ ter sede e administração no País; (c) setenta por cento do capital total e votante devem ser de titularidade, direta ou indireta, de brasileiros natos ou naturalizados há mais de dez anos; e $(d)$ as atividades de gestão e responsabilidade editorial (e, no caso da programadora, seleção dos conteúdos do canal de programação) devem ser privativas de brasileiros natos ou naturalizados há mais de 10 anos.

Para que esse ator, adicionalmente, seja qualificado como "independente", deve atender aos seguintes requisitos:

(i) para produtoras brasileiras independentes: a) não ser controladora, controlada ou coligada a programadoras, empacotadoras, distribuidoras ou concessionárias de serviço de radiodifusão de sons e imagens; b) não estar vinculada a instrumento que, direta ou indiretamente, confira ou objetive conferir a sócios minoritários, quando estes forem programadoras, empacotadoras, distribuidoras ou concessionárias de serviços de radiodifusão de sons e imagens, direito de veto comercial ou qualquer tipo de interferência comercial sobre os conteúdos produzidos; e c) não manter vínculo de exclusividade que a impeça de produzir ou comercializar para terceiros os conteúdos audiovisuais por ela produzidos.

(ii) para programadoras brasileiras independentes: a) não ser controladora, controlada ou coligada a empacotadora ou distribuidora; e b) não manter vínculo de exclusividade que a impeça de comercializar, para qualquer empacotadora, os direitos de exibição ou veiculação associados aos seus canais de programação. 
A exemplo da proposta apresentada anteriormente pelo Deputado Jorge Bittar, o substitutivo estabeleceu dois tipos de cotas de conteúdo: a "cota de canal" e a "cota de pacote".

A cota de canal estabelece que nos canais de espaço qualificado, no mínimo três horas e trinta minutos semanais dos conteúdos veiculados no horário nobre deverão ser brasileiros e integrar espaço qualificado, e metade deverá ser produzida por produtora brasileira independente.

Já a cota de pacote é composta por uma série de regras específicas, a seguir sintetizadas: $(i)$ em todos os pacotes ofertados ao assinante, a cada três canais de espaço qualificado existentes no pacote, ao menos um deverá ser canal brasileiro de espaço qualificado, até o limite de 12 canais brasileiros; (ii) dessa parcela mínima de canais brasileiros de espaço qualificado, pelo menos um terço deverá ser programado por programadora brasileira independente; (iii) dos canais brasileiros de espaço qualificado a serem veiculados nos pacotes, ao menos dois canais deverão veicular, no mínimo, doze horas diárias de conteúdo audiovisual brasileiro produzido por produtora brasileira independente, três das quais em horário nobre; (iv) a programadora de pelo um desses canais não poderá ser controlada, controladora ou coligada a concessionária de serviço de radiodifusão de sons e imagens; (v) nos pacotes em que houver canal de programação gerado por programadora brasileira que possua majoritariamente conteúdos jornalísticos no horário nobre, deverá ser ofertado pelo menos um canal adicional de programação com as mesmas características no mesmo pacote ou na modalidade avulsa de programação; e (vi) as programadoras desse canais não poderão deter relação de controle ou coligação entre si.

Foi estabelecida regra de transição para a implementação das cotas, permitindo que ao longo dos dois primeiros anos de vigência da lei o número de horas de programação sob regime de cotas seja aumentado de forma gradativa. Além disso, as regras sobre cotas têm vigência de apenas doze anos a partir da aprovação da lei.

A CCTCI aprovou também a alteração do artigo 86 da LGT, permitindo às concessionárias de STFC a exploração de oturos serviços de telecomunicações desde que observados determinados princípios relativos à competição no setor, à defesa dos usuários e à proteção dos bens reversíveis.

Por fim, a CCTCI determinou a possibilidade de migração das atuais prestadoras de TV a Cabo, MMDS, DTH e TVA para o SAC, estabelecendo Revista de Direito, Estado e Telecomunicações, v. 2, n. 1, p. 231-258 (2010) 
que a partir da data de aprovação do PL não seriam mais outorgadas novas concessões ou autorizações para esses serviços.

\section{Discussão na CCJC}

Por fim, o projeto foi encaminhado à CCJC. O parecer do Deputado relator Eduardo Cunha, de março de 2010, rejeitou todas as emendas que apontavam supostas inconstitucionalidades e propôs quatro emendas supressivas, todas direcionadas para as outorgas de TVA. Em seu parecer, deixou claro que os artigos do PL que estabeleciam regras especiais para os detentores de tais outorgas criavam "uma casta de privilegiados, para os quais, não obstante serem ex-detentores de outorgas (já vencidas) se atribui direitos excepcionais não aplicáveis aos demais interessados". Em sua visão, o "privilégio" estaria "dirigido para pessoas jurídicas bem definidas, que receberam no passado tais autorizações de forma não onerosa, e na forma assim prevista, ampliam os privilégios adquiridos no passado e passariam a ser pessoas jurídicas para os quais não valeriam as restrições de controle da cadeia de valor e os únicos distribuidores que tem ampla liberdade operacional no âmbito da produção de conteúdo".

\section{Prováveis encaminhamentos futuros}

Tem-se a expectativa de que com a conclusão dos debates na Comissão de Constituição e Justiça e Cidadania da Câmara dos Deputados, o PL 29 seja encaminhado ao Senado e apensado ao PLS 280/2007, de autoria do Senador Flexa Ribeiro.

Na mídia especializada, tem sido novamente aventada a possibilidade de separar o projeto em dois, para que os temas de maior consenso sejam aprovados com maior celeridade. Dada a polêmica experimentada na Câmara dos Deputados, é possível que se ocorrer tal separação, a discussão sobre a flexibilização das restrições de acesso ao mercado avance a passos largos, enquanto o debate sobre cotas de conteúdo permaneça, por mais alguns anos, travado no Poder Legislativo.

\section{Os diversos grupos de interesse envolvidos}

Tanto no Senado quanto na Câmara, com o intuito de instruir os PLs, foram realizadas audiências públicas com a participação de representantes 
dos setores interessados: radiodifusores (ABERT, ABRA e ABTU), produtores independentes (ABPITV), empresas de telefonia fixa (ABRAFIX), empresas de telefonia celular (ACEL), prestadoras de serviços de telecomunicações competitivas (TELCOMP), empresas de TV por assinatura (ABTA), programadores de televisão (ABPTA), jornalistas (FENAJ), entidades governamentais (ANATEL, ANCINE, MINICOM e CADE) e sociedade civil (FNDC e INTERVOZES).

As inúmeras emendas apresentadas aos substitutivos ao PL 29 são um claro reflexo dos embates entre os diferentes atores do setor de telecomunicações. Sem ignorar as inúmeras variantes possíveis em torno dos diversos pontos de vista externados, é possível expor, de forma simplificada, o posicionamento dos principais grupos de interesses.

\section{Radiodifusoras: o temor da entrada das teles no mercado de conteúdo e o alerta contra a dominação cultural estrangeira}

A Associação Brasileira de Rádio e Televisão (ABERT) tem se manifestado de forma veemente em defesa do conteúdo brasileiro, sustentando a necessidade de a legislação brasileira oferecer robusta proteção contra a entrada indiscriminada dos grandes grupos internacionais no mercado de produção, programação e provimento de conteúdo. Nessa linha, procura demarcar as diferenças entre serviços de radiodifusão e de telecomunicações, salientando a importância de se manter os conteúdos hoje veiculados nas mãos de brasileiros.

Nesse passo, a ABERT alerta contra a ameaça da entrada das teles e das grandes produtoras mundiais de mídia no negócio da produção de conteúdo, o que, em sua visão, abriria a porta para a dominação cultural do mercado brasileiro. Segundo a ABERT, o meio de assegurar o fortalecimento da cultura, da história e dos valores brasileiros é a preservação da produção, da programação e do provimento de conteúdos brasileiros por empresas brasileiras, admitindo-se, porém, o desenvolvimento e diversificação dos meios de distribuição de tais conteúdos ${ }^{8}$. A mensagem é clara: para as

\footnotetext{
${ }^{8}$ Veja-se trecho da dramática fala de Evandro Guimarães, representante da ABERT, na Audiência pública conjunta das Comissões de Desenvolvimento Econômico, Indústria e Comércio e de Ciência e Tecnologia, Comunicação e Informática, da Câmara dos Deputados, em 15.08.07: "A comunicação social é o editorial, o falar de brasileiros para brasileiros, o convívio de brasileiros emissores, receptores, que, Revista de Direito, Estado e Telecomunicações, v. 2, n. 1, p. 231-258 (2010)
} 
primeiras etapas da cadeia produtiva - produção, programação e provimento - devem ser impostas restrições quanto ao capital estrangeiro semelhantes ou idênticas às existentes para a radiodifusão, flexibilizando-se, porém, sua distribuição. Há uma aberta rejeição ao estabelecimento de cotas, à classificação indicativa e a qualquer medida que possa, na visão da associação, representar uma "interferência" na liberdade de expressão.

\section{Teles: a busca de novas receitas e o pleito de abertura do mercado em razão da convergência}

As empresas telefônicas, tanto fixas quanto móveis, interessadas no aumento de suas receitas por meio da oferta de novos serviços, têm salientado a necessidade de se levar em conta a realidade decorrente da evolução tecnológica, chamando a atenção para a inevitabilidade da convergência, que possibilita a recepção de informação independentemente da plataforma ou da infra-estrutura utilizada. Assim, sustentam a necessidade de mudança das regras para estímulo a novos investimentos na expansão na infraestrutura.

A Associação Brasileira de Concessionárias de STFC (ABRAFIX) tem centrado seu poder de fogo na necessidade de mudanças na regulamentação da televisão por assinatura, para que possam ofertar a seus clientes serviços englobando voz, acesso à banda larga e à Internet e televisão por assinatura, o que, em sua visão, contribuiria para a expansão do mercado, para a redução de preços e para o estímulo à criação de mais programações, em especial por produtoras nacionais e independentes. A ABRAFIX defende a atualização e harmonização da legislação, contemplando o fim da regulação

trocando essa energia altamente produtiva, constroem o alter ego e o ego da Nação. Insisto: a Constituição é a mãe do marco regulatório e determina que rádio, jornal, televisão e revistas sejam submetidos a um conjunto enorme de obrigações regulatórias; estão obrigados a respeitar uma composição de capital na qual $70 \%$ deste devem pertencer obrigatoriamente a brasileiros, seja capital votante, seja preferencial. (...) Defender comunicação de cidadãos para os seus concidadãos é defender um mundo plural, um mundo que segura um santo sem derrubar um outro, que não anula a possibilidade de se ser moderno nas plataformas, na estrutura de distribuição, nos serviços, e preserva a alma, com o corpo saudável. O corpo já foi, a alma precisa ser integralmente preservada". (cfr. notas taquigráficas disponíveis em http://www2.camara.gov.br/comissoes/cctci/Eventos/notastaquigraficas/nt-ap-15-8-07-pl-29-2007/, consultadas em 07.02.08). 
por tecnologia, o que abrangeria a revogação da Lei de TV a Cabo, "respeitados os canais de acessos públicos, de filmes brasileiros e outros dispositivos sociais importantes proporcionados por aquela lei; o equacionamento do mecanismo "must-carry", de modo a respeitar os direitos dos radiodifusores e a possibilidade de se assegurar maior representação de conteúdos nacionais nas grades de programação, inclusive com o estabelecimento de quotas"9.

Já a Associação Nacional das Operadoras Celulares - ACEL tem se manifestado quanto à necessidade de criação de um ambiente favorável para a produção de conteúdo nacional, de garantia de que haja alternativas de canais de distribuição e de liberdade de escolha do usuário quanto ao conteúdo que deseja receber. Em outras palavras, defende a liberdade de produção, distribuição e consumo de conteúdo nacional, incentivando também a criação de mecanismos de fomento à produção independente, de modo a reduzir a dependência das grandes programadoras nacionais. A ACEL sustenta, ainda, a necessidade de eliminar "barreiras artificiais ao ingresso de novos atores em qualquer ponto da cadeia de valor", referindose, especificamente, a assimetrias regulatórias com base na tecnologia utilizada ou na origem do capital.

$\mathrm{Da}$ análise das manifestações das radiodifusoras e das empresas de telefonia, pode-se depreender que a chave de braço entre elas não diz respeito à produção de conteúdo (as teles têm declarado não terem, neste momento, capacidade ou vontade de entrar nesse mercado), mas à programação/empacotamento de conteúdo e à conseqüente disputa por receitas publicitárias.

\section{Empresas de TV por assinatura: a rejeição à limitação de capital e a dubiedade quanto à entrada das concessionárias no mercado de televisão por assinatura}

A Associação Brasileira de Televisão por Assinatura - ABTA tem se manifestado nas audiências públicas procurando, por um lado distinguir os serviços de televisão por assinatura (serviços de telecomunicações) dos

\footnotetext{
${ }^{9} \mathrm{Cfr}$. notas taquigráficas disponíveis em http://www2.camara.gov.br/comissoes/ cctci/Eventos/notas-taquigraficas/nt-ap-15-8-07-pl-29-2007/, consultadas em março de 2010. 
serviços de radiodifusão; e, por outro, diferenciar as diversas etapas da cadeia produtiva do conteúdo audiovisual. Segundo a associação, é imprescindível diferenciar a produção (ou provimento), o transporte e a distribuição de conteúdo, deixando claro que $(i)$ as regras incidentes sobre a produção de conteúdo - como a liberdade de expressão, o pluralismo e a preservação da cultura nacional - não são as mesmas incidentes sobre (ii) o transporte de conteúdo - como a qualidade de transmissão, a interconexão e as normas de planejamento urbano -, que, por sua vez, diferem completamente daquelas incidentes sobre (iii) a distribuição de conteúdo como as regras de proteção do consumidor e as questões relativas a publicidade e patrocínio.

Nessa linha, a ABTA protesta contra a existência de assimetrias e restrições ao capital estrangeiro no transporte de conteúdo ${ }^{10}$, sustentando que não se deve impor limites à entrada de capitais estrangeiros na construção de infra-estrutura. No que tange ao conteúdo, a associação defende que não haja qualquer bloqueio à livre entrada de conteúdos internacionais, mas que haja mecanismos de fomento e incentivo à produção nacional.

A ABTA alerta também para a necessidade de assegurar que a entrada das teles no mercado de TV por assinatura não implique no transbordamento, para um mercado competitivo, de uma estrutura monopolista, como a que existe no STFC local.

É importante chamar a atenção para a dubiedade que tem marcado algumas manifestações da ABTA, resultante de serem duas de suas mais importantes associadas, Net e a TVA, vinculadas por parcerias comerciais ou ligações societárias a empresas prestadoras de STFC (a Embratel e a Telefônica, respectivamente).

${ }^{10}$ Veja-se a fala de Alexandre Annenberg na Audiência pública conjunta das Comissões de Desenvolvimento Econômico, Indústria e Comércio e de Ciência e Tecnologia, Comunicação e Informática, da Câmara dos Deputados, em 15.08.07: "Existe aí uma assimetria que causa espécie e desequilibra claramente o aspecto competitivo. E mais: desestimula - e esse é um ponto que os senhores devem aprofundar - a vinda de recursos externos, que são absolutamente essenciais para investimento em infraestrutura, como, por exemplo, redes de cabo. À medida que discriminamos a origem do capital para a construção de redes de cabo, estamos dando um tiro no pé. (...) Se for preciso fazer restrições à origem de capital, que jamais elas sejam sobre a construção de redes, pelo amor de Deus!”. 


\section{Outros atores: programadores, produtores independentes e prestadoras competitivas de telecomunicações}

A Associação Brasileira de Programadores de Televisão por Assinatura (ABPTA) é o braço brasileiro da Television Association of Programmers (TAP), sediada em Miami. Como representante dos principais canais internacionais, a associação tem repudiado a criação ou ampliação de restrições ao capital estrangeiro, alegando que estas violam garantias constitucionais de acesso à informação e criam reservas de mercado para grandes grupos de mídia brasileiros.

Já a Associação Brasileira de Produtores Independentes de Televisão ABPI-TV tem criticado a falta de regulamentação da produção de conteúdo de TV, a verticalização da produção, que acarreta uma menor diversidade de conteúdo, e a falta de mecanismos de financiamento à produção independente. Nessa linha, tem se manifestado quanto à necessidade de oferecer incentivos e fomento à produção independente, de modo a permitir o crescimento do mercado doméstico e impedir o monopólio de produção.

A Associação Brasileira das Prestadoras de Serviços de Telecomunicações Competitivas (TELCOMP), por sua vez, tem centrado suas manifestações na etapa da distribuição de conteúdo, sustentando a necessidade de que os meios de distribuição estejam "pulverizados". Assim, sugere a eliminação de qualquer limitação ao capital estrangeiro e a implementação da desagregação de redes (unbundling), para que sejam diminuídos os efeitos anticompetitivos decorrentes da concentração da infraestrutura.

\section{Sociedade civil: a necessidade de avançar na democratização das comunicações}

Por fim, vale destacar que a sociedade civil tem, tanto na Câmara quanto no Senado, sido chamada a opinar e participar das discussões públicas referentes aos PLs. Não obstante a nítida influência das forças do mercado no processo legislativo, e a despeito das críticas que podem ser direcionadas aos procedimentos de audiência pública - e.g. escassez de tempo, inevitável superficialidade das discussões, duvidosa capacidade de influência, publicidade limitada -, fato é que a sociedade civil tem conseguido se fazer ver e ouvir, demarcando claramente suas posições nas duas casas do Congresso Nacional. 
Entidades como o Fórum Nacional pela Democratização da Comunicação (FNDC) e o Coletivo Brasil de Comunicação Social (INTERVOZES) têm se manifestado pela necessidade de "quebra" da concentração vertical da cadeia de valor e da propriedade cruzada, bem como de oferta de conteúdos representativos da diversidade e pluralidade, em consonância com os mandamentos constitucionais. Ademais, reclamam o acesso público aos sistemas de programação e distribuição de conteúdos e, de modo geral, uma ampliação dos mecanismos de participação e controle social.

\section{Conclusões}

A discussão precedente abordou inúmeras questões relativas à comunicação de massa, envolvendo aspectos econômicos, mercadológicos, culturais e sociais, tocando em interesses diversos e por vezes antagônicos. À guisa de conclusão, dois pontos merecem destaque.

Em primeiro lugar, é necessário que o debate acerca do novo marco legal para a comunicação de massa seja aprofundado e ampliado. A cobertura jornalística tem se limitado à imprensa especializada e as audiências públicas são na prática, por sua própria natureza, restritas aos setores diretamente interessados. A participação da sociedade civil, embora contundente, tem sua influência mitigada em face da ação dos grandes poderes econômicos e dos interesses pessoais de muitos parlamentares no setor de comunicação de massa. Em vista do importantíssimo papel desempenhado pela mídia na consolidação da democracia, a ampliação do debate é recomendável.

Em segundo lugar, é preciso que o novo marco legal para o setor represente, efetivamente, uma evolução no que concerne à democratização da comunicação. A adequada demarcação e regulação das etapas da cadeia produtiva é elemento importante para evitar a concentração vertical e permitir a representação pluralista de pontos de vista diversificados. É preciso definir que tipo de conteúdo merece uma especial proteção, de que modo tal conteúdo será protegido e de que maneiras sua produção será fomentada. Sobretudo, é necessário definir critérios para a concretização dos comandos constitucionais relativos à comunicação social, resgatando-os da condição de eternas normas programáticas. Nesse sentido, espera-se que a 
imposição de obrigações para as prestadoras de serviços de televisão por assinatura impulsione o debate acerca do estabelecimento de obrigações simétricas para as empresas de radiodifusão, cujos serviços são oferecidos de forma aberta e gratuita a toda a população brasileira. 